\title{
The Clinical Values of Serum Markers in the Early Prediction of Hepatocellular Carcinoma
}

\author{
Bo Li, ${ }^{1}$ Boan Li, ${ }^{1}$ Tongsheng Guo, ${ }^{1}$ Zhiqiang Sun, ${ }^{1}$ Xiaohan Li, ${ }^{1,2}$ Xiaoxi Li, ${ }^{1}$ \\ Han Wang, ${ }^{1}$ Weijiao Chen, ${ }^{1}$ Peng Chen, ${ }^{1}$ and Yuanli Mao ${ }^{1,2}$ \\ ${ }^{1}$ Center for Clinical Laboratory, 302 Military Hospital, Beijing, China \\ ${ }^{2}$ Graduate Student Team, Medical University of PLA, Beijing, China
}

Correspondence should be addressed to Yuanli Mao; pipi780816@aliyun.com

Received 9 December 2016; Accepted 9 March 2017; Published 30 April 2017

Academic Editor: Tzi Bun Ng

Copyright (C) 2017 Bo Li et al. This is an open access article distributed under the Creative Commons Attribution License, which permits unrestricted use, distribution, and reproduction in any medium, provided the original work is properly cited.

\begin{abstract}
The early prediction values of diagnostic markers for hepatocellular carcinoma (HCC) are still unclear at present. This study evaluated the prediction value of ten serum markers in HCC. A total of 109 cases of hepatic cirrhosis patients were followed up for 36 months and the relationship between the lifetime risk of developing HCC and levels of serum markers was analyzed. 31.2 (34/109) percent of hepatic cirrhosis patients developed HCC during the study's timeframe. Higher alpha-fetoprotein (AFP), alphafetoprotein-L3 (AFP-L3), alanine aminotransferase (ALT), and AFP-L3/AFP ratio levels are potential risk factors for malignization in hepatic cirrhosis patients ( $\mathrm{RR}=2.99,2.92,2.72$, and 2.34); serum Golgi protein 73 (GP73) level of hepatic cirrhosis patients decreased significantly after developing HCC $(t=2.212 ; p=0.041)$. The detection of ALT, AFP, AFP-L3, and GP73 has a certain guiding significance to predict the risk of HCC in hepatic cirrhosis patients.
\end{abstract}

\section{Introduction}

Hepatocellular carcinoma (HCC) is the fifth leading cause of cancer death worldwide and about 500,000 people die of it each year [1]. More than $90 \%$ of HCC cases develop as a consequence of underlying liver diseases, and hepatic cirrhosis occurs in $80 \%$ of cases [2-4]. More than $60 \%$ of patients are diagnosed with late-stage disease after metastasis has occurred [5], resulting in an overall 5-year survival rate of $<16 \%$ [6]. If appropriate treatments are performed in early stage, the 5-year survival rates of HCC patients will exceed $75 \%$ [7]. Thus, detection of HCC at an early stage significantly impacts outcomes in patients. The American Association for the Study of Liver Diseases (AASLD) once recommended that AFP and ultrasound examination were used for HCC surveillance in hepatic cirrhosis population, but analysis of recent studies shows that AFP determination lacks adequate sensitivity and specificity for effective surveillance [8]. Novel biomarkers are urgently needed for the screening of HCC to reduce its high mortality; many studies have reported that lens culinaris agglutinin reactive AFP (AFP-L3) and Golgi protein 73 (GP73) are effective for the HCC early diagnosis [9-11], but there has been a lack of clinical follow-up from hepatic cirrhosis stage to HCC. The goal of the present study is to estimate the risk prediction value of some serum markers during the progression from hepatic cirrhosis to HCC.

\section{Materials and Methods}

2.1. Subject. All study subjects were enrolled at 302 military hospital, Beijing, China, and were followed up during the study period of 36 months, until confirming HCC diagnosis or the date of study end (December 31, 2016). The study population included any hepatic cirrhosis patients over 30 years old who were identified as HBV or HCV infected patients for at least 5 years. Some patients with the following conditions were excluded: patients who were diagnosed with HCC at starting point of this study; patients with other systemic disease such as diabetes and hypertension; patients after surgery, interventional therapy, radiotherapy, chemotherapy, and other invasive treatment; patients suffering from severe 
complications such as upper gastrointestinal bleeding and hepatic encephalopathy. The final diagnosis was made by liver histopathology or MRI based on guidelines from Ministry of Health of the People's Republic of China [12] and guideline from the Chinese Society of Hepatology and the Chinese Society of Infectious Diseases $[13,14]$. The study procedures were approved by the ethics committee of the 302 Military Hospital of China and written informed consent was obtained from each subject.

2.2. Laboratory Tests. A total of ten routine laboratory tests were chosen to be analyzed; they were albumin (ALB), total bilirubin (TBil), alanine transaminase (ALT), platelet count (PLT), prothrombin time $(\mathrm{Pt}(\mathrm{s}))$, prothrombin time activity (Pt(a)), AFP, GP73, AFP-L3, and AFP-L3/AFP ratio (L3/ AFP). Clinical chemistry tests were applied by an automatic biochemical analyzer (AU5400, Olympus, Japan). PLT was detected using Hematology Analyzer (XE-1800, SYSMEX, Japan). $\mathrm{Pt}(\mathrm{s})$ and $\mathrm{Pt}(\mathrm{a})$ were measured in automated coagulation instrument (CA-7000, SYSMEX, Japan). AFP and AFPL3 were measured by Automated Immunoassay Analyzer (COBAS6000, ROCHE, Switzerland). Kits for the enzymelinked immunosorbent assay for GP73 were obtained from Hotgen Biotech (Beijing, China).

2.3. Study Protocol and Statistical Analysis. The incidences of HCC during the study period were analyzed by examination of medical records. Ten markers at starting point of this study were compared between patients with abnormal serum biomarkers levels, denoted as the positive groups, and those with normal levels, denoted as negative groups. The judgment criteria are as follows: ALB $<35 \mathrm{~g} / \mathrm{l}$, TBIL $>19 \mu \mathrm{mol} / \mathrm{L}, \mathrm{ALT}>$ $40 \mathrm{U} / \mathrm{L}, \mathrm{PLT}<100 \times 10^{9} / \mathrm{L}, \mathrm{AFP}>10 \mathrm{ng} / \mathrm{mL}, \mathrm{PT}(\mathrm{s})>13 \mathrm{~s}$, PT(a) < 75\%, AFP-L3 > $1.0 \mathrm{ng} / \mathrm{mL}$, GP73 > $150 \mathrm{ng} / \mathrm{mL}$, and AFP-L3/AFP > 0.05. After 3 years' follow-up, cumulative incidence (CI) and relative risk (RR) of ten markers were calculated for each group to identify potential risk factors for HCC. A chi-square test was performed to compare the incidence rate between the positive and negative groups in our study cohort. All markers at starting point of this study were compared between patients who had developed HCC within 3 years and those who had not developed HCC to explore the early prediction value of serum markers. In order to investigate the dynamic change of the serum markers during the progression of HCC, we had compared all markers in HCC patients for two time points: starting point and the time they are diagnosed with HCC. Normally distributed data were analyzed with Student's $t$-tests. Other data were tested by the Wilcoxon method. To assess the role of all markers as diagnostic predictive markers for HCC, receiver operating characteristic curves (ROC) were plotted and the area under the curve (AUC) was calculated. All statistical analysis was performed using SPSS 14.0 software (SPSS, Inc., Chicago, IL).

\section{Results}

3.1. Study Sample. A total of 161 cases were diagnosed as hepatic cirrhosis during the study period. Fifty-two cases were excluded (35 were excluded due to history of other systemic
TABLE 1: The demographic data of the patients.

\begin{tabular}{lccc}
\hline & HCC-group & Non-HCC group & $p$ value \\
\hline Gender & & & \\
Male & 22 & 44 & 0.550 \\
Female & 12 & 31 & \\
Age (years) & $56(35-83)$ & $52(37-74)$ & 0.118 \\
\hline
\end{tabular}

diseases, 3 participants were excluded due to excessive missing data, and 14 patients with confirmed severe complications were excluded). Therefore, a total of 109 patients met the inclusion criteria and were analyzed. All participants had a mean age of $53.9(\mathrm{SD}=9.7)$ years, were $60.6 \%$ male, $94.5 \%$ were with a history of HBV infection (see Table 1). During 36 months of follow-up, 34 out of 109 cirrhotic patients were confirmed to have HCC eventually (31.2\%).

3.2. Early Warning Value of Serum Markers for HCC. We compared the serum markers levels at starting point between patients who had developed HCC and those who had not developed HCC; the results demonstrated that there were 4 markers, including AFP, AFP-L3, ALT, and AFP-L3/AFP ratio, that were statistically significant $(p<0.05)$; see Table 2 and Figure 1. It is evident that the increase of AFP, AFP-L3, and ALT levels in serum and AFP-L3/AFP ratio are potential precursors of HCC; thus regular monitoring of these markers seems necessary in hepatic cirrhosis patients.

The risk factors analysis showed that incidence rate of HCC in patients with high AFP, AFP-L3, ALT, and AFPL3/AFP levels were extremely significantly higher than that those with normal levels $(\mathrm{RR}=2.99, p=0.000$; $\mathrm{RR}=2.92$, $p=0.000 ; \mathrm{RR}=2.72, p=0.001 ; \mathrm{RR}=2.34, p=0.003)$. Our results revealed that cirrhotic patient with higher levels of AFP, AFP-L3, AFP-L3/AFP ratio, or ALT had a risk of developing HCC and these four markers were risk factors for HCC. In contrast to the previous studies, we find that high GP73 level seemed to be a protective factor for HCC, because elevated GP73 levels were associated with a lower risk of incident HCC (see Table 3).

3.3. Predictive Value of Serum Markers for HCC. ROC analysis was used to determine whether serum markers are powerful to predict HCC in the cirrhotic population. The results showed that AFP, AFP-L3, and ALT had relatively good predictive power for HCC progression; AUC were 0.736, 0.744 , and 0.693 , respectively (see Table 4 , Figure 2 ). The multiple regression analysis suggested that the combination of three markers could not significantly improve the predictive efficacy; the best combination was ALT and AFP, which obtained AUC of 0.780; see Table 4, Figure 3.

3.4. Dynamic Change of the Serum Markers during the Progression of HCC. Among the $34 \mathrm{HCC}$ cases, 17 were excluded due to incomplete data or nonavailable data. We analyzed the dynamic change of the ten markers in other 17 cases during the progression of HCC, and we found that serum GP73 level was significantly decreased $(p=0.041)$ in patients when they were identified with HCC. The concentration of 


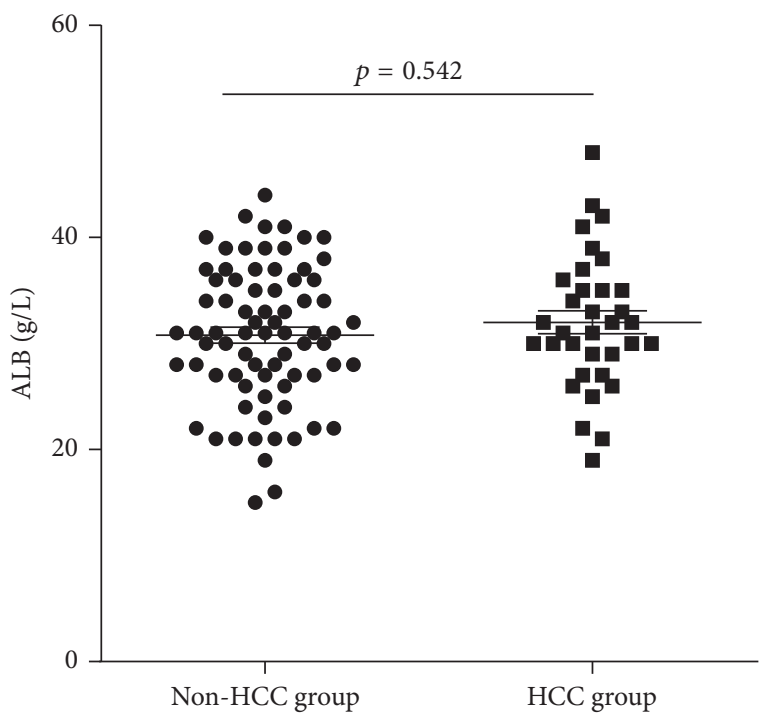

(a)

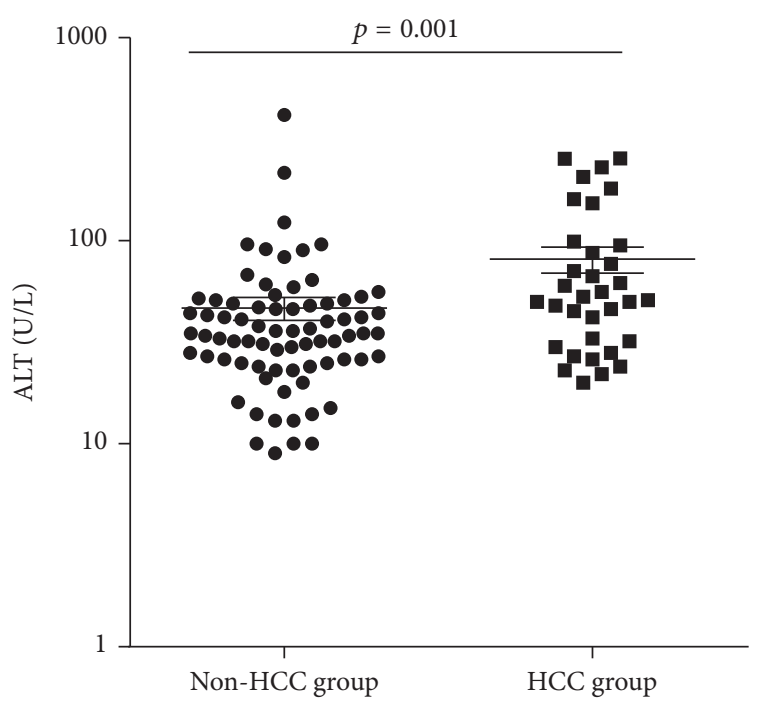

(c)

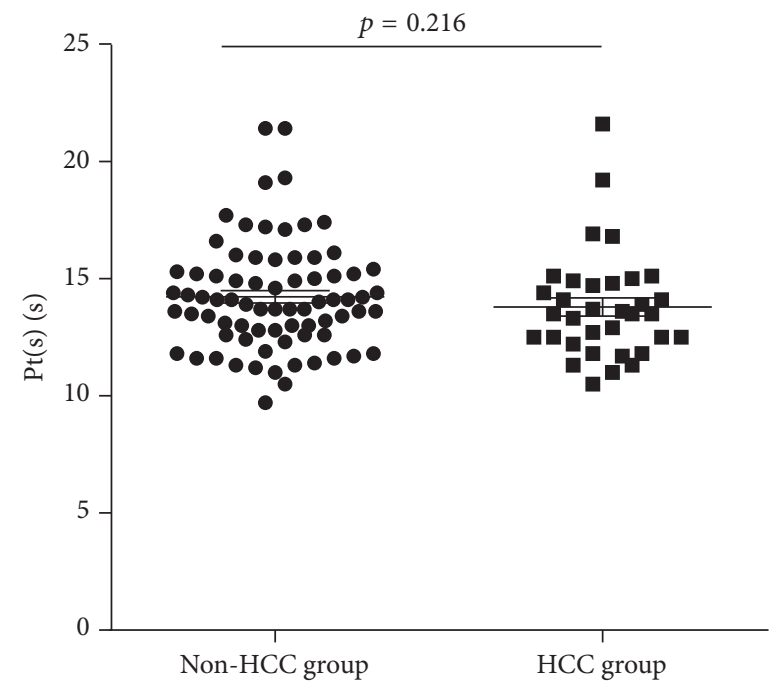

(e)

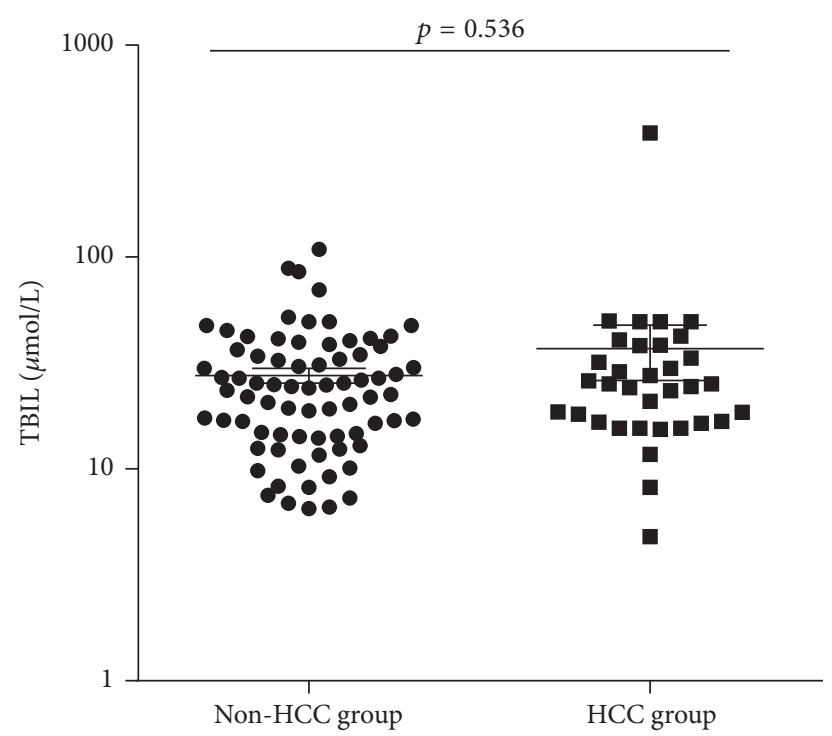

(b)

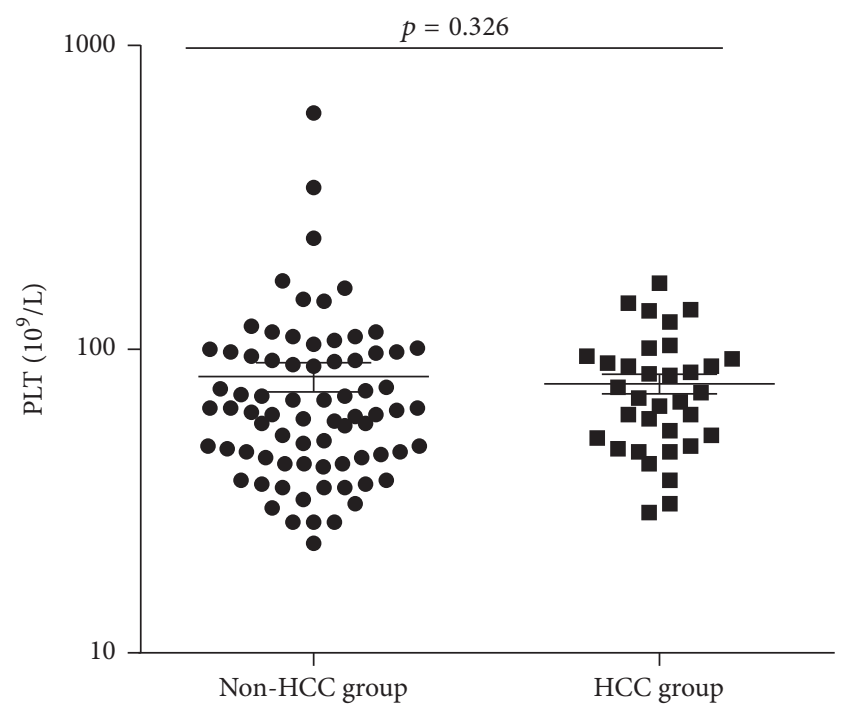

(d)

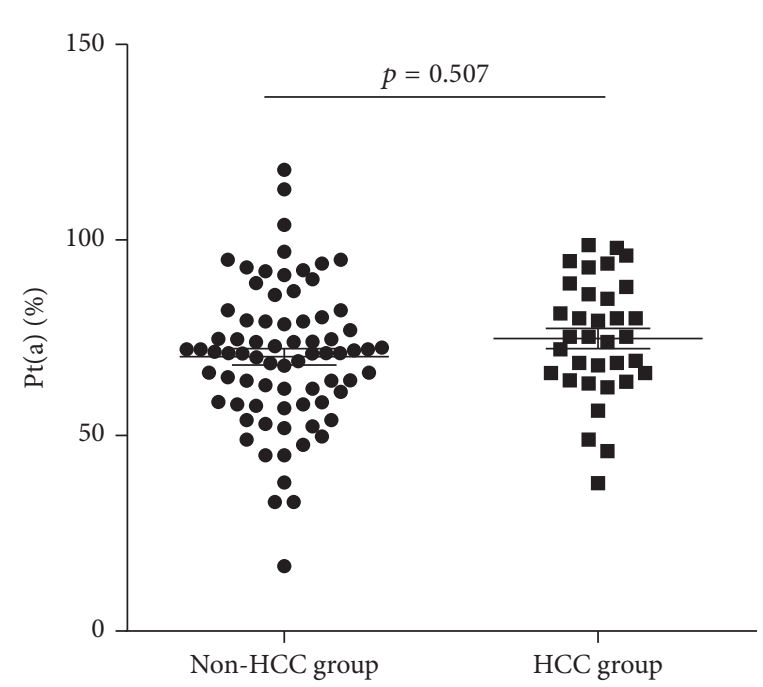

(f)

FIGUre 1: Continued. 


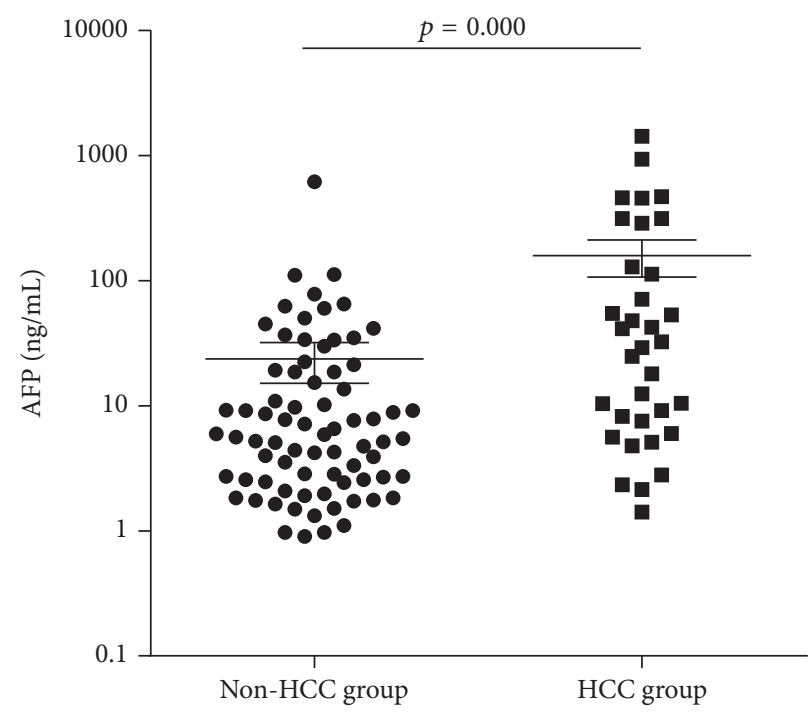

(g)

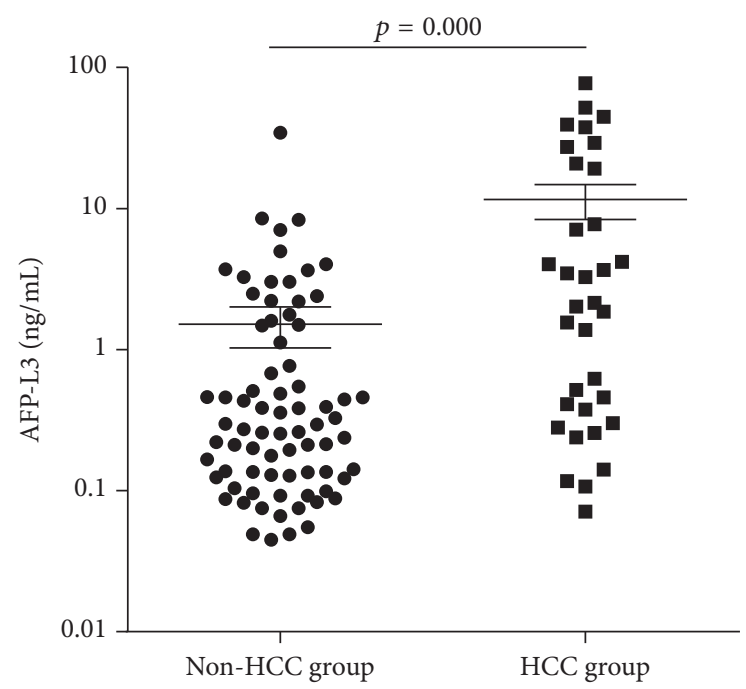

(i)

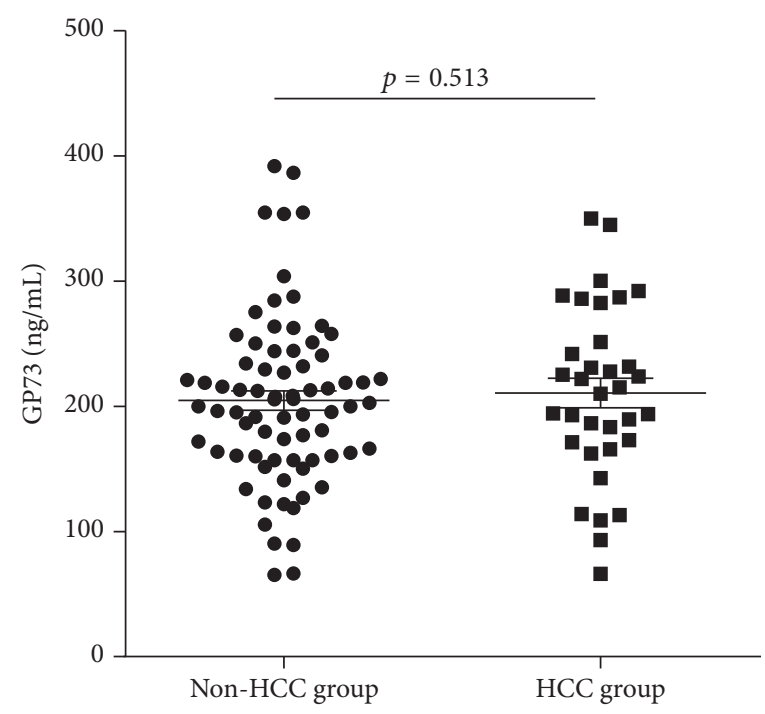

(h)

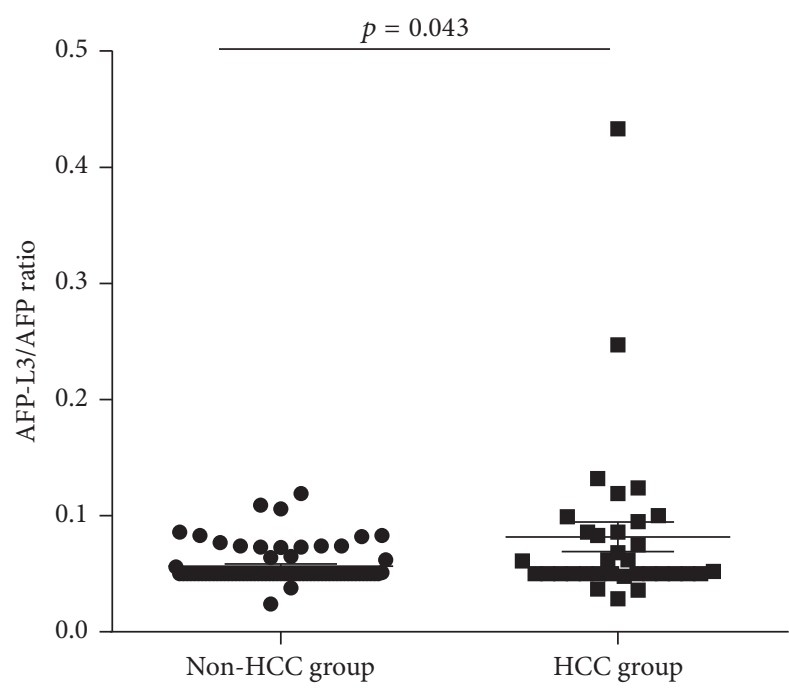

(j)

FIGURE 1: The difference of 10 biomarkers levels between patients who had developed HCC within 3 years and those who had not developed HCC.

TABLE 2: The statistical analysis of the levels of serum markers between HCC group and non-HCC group.

\begin{tabular}{|c|c|c|c|c|c|c|}
\hline \multirow{2}{*}{ Markers } & \multicolumn{2}{|r|}{ HCC group } & \multicolumn{2}{|c|}{ Non-HCC group } & \multirow{2}{*}{$T / Z$ values } & \multirow{2}{*}{$p$ values } \\
\hline & $n$ & Statistical description & $n$ & Statistical description & & \\
\hline $\operatorname{ALB}(\mathrm{g} / \mathrm{L})$ & 34 & $32.0 \pm 6.32$ & 75 & $30.8 \pm 6.5$ & 0.897 & 0.542 \\
\hline TBIL $(\mu \mathrm{mol} / \mathrm{L})$ & 34 & $24.85(4.8-385.6)$ & 75 & $24.1(6.5-109)$ & -0.618 & 0.536 \\
\hline ALT (IU/L) & 34 & $52(20-254)$ & 75 & $35(9-416)$ & -3.212 & 0.001 \\
\hline $\operatorname{PLT}\left(10^{9} / \mathrm{L}\right)$ & 34 & $70.5(29-165)$ & 75 & $62(23-599)$ & -0.981 & 0.326 \\
\hline $\operatorname{Pt}(\mathrm{s})(\mathrm{s})$ & 34 & $13.5(10.5-21.6)$ & 75 & $14.00(9.7-21.4)$ & -1.237 & 0.216 \\
\hline $\operatorname{Pt}(\mathrm{a})(\%)$ & 34 & $74.8 \pm 15.0$ & 75 & $70.2 \pm 18.0$ & 1.313 & 0.507 \\
\hline $\operatorname{AFP}(n g / m L)$ & 34 & $30.88(1.41-1432)$ & 75 & $5.62(0.9-617.4)$ & -3.944 & 0.000 \\
\hline GP73 (ng/mL) & 34 & $212.6(66.12-350)$ & 75 & $202.8(65.38-391.9)$ & -0.654 & 0.513 \\
\hline AFP-L3 (ng/mL) & 34 & $2.09(0.07-77.45)$ & 75 & $0.273(0.05-34.4)$ & -4.068 & 0.000 \\
\hline AFP-L3/AFP ratio & 34 & $0.051(0.03-0.43)$ & 75 & $0.05(0.02-0.12)$ & -2.019 & 0.043 \\
\hline
\end{tabular}

Normally distributed data were reported as mean $\pm \mathrm{SD}$. Other data were reported as median (minimum, maximum); $n$ : number of samples. 


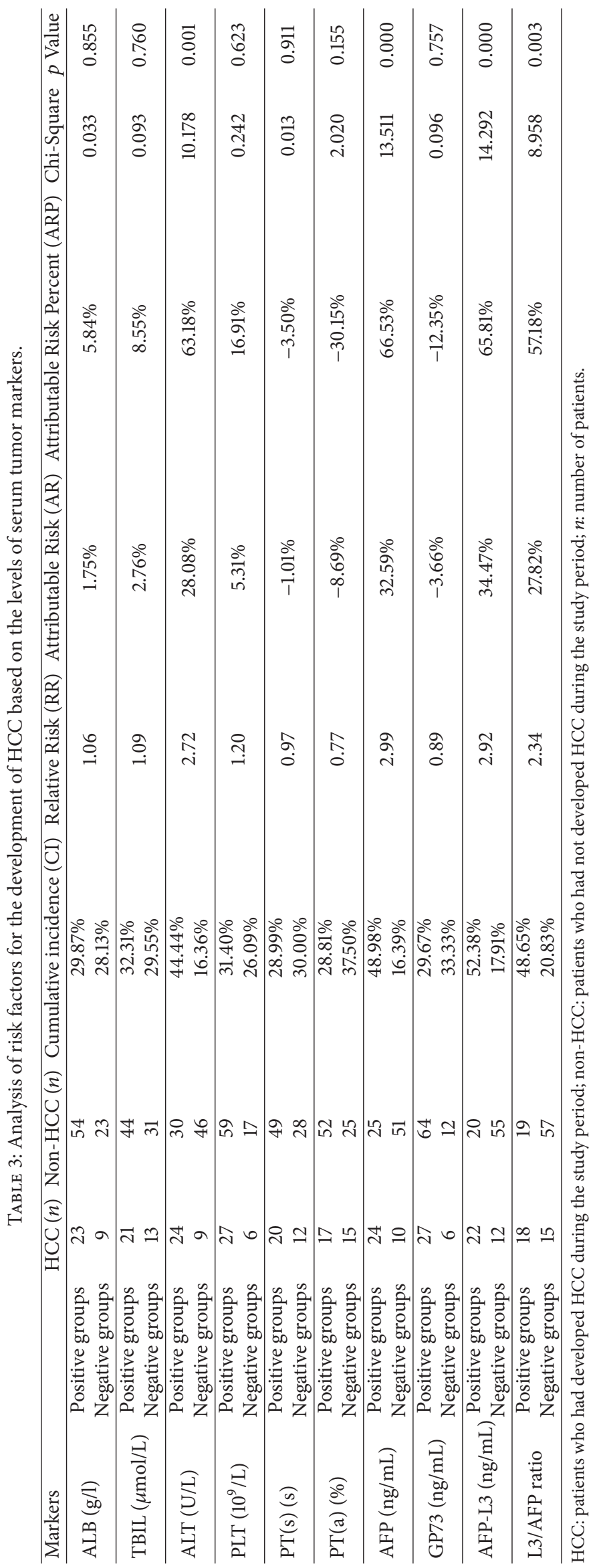




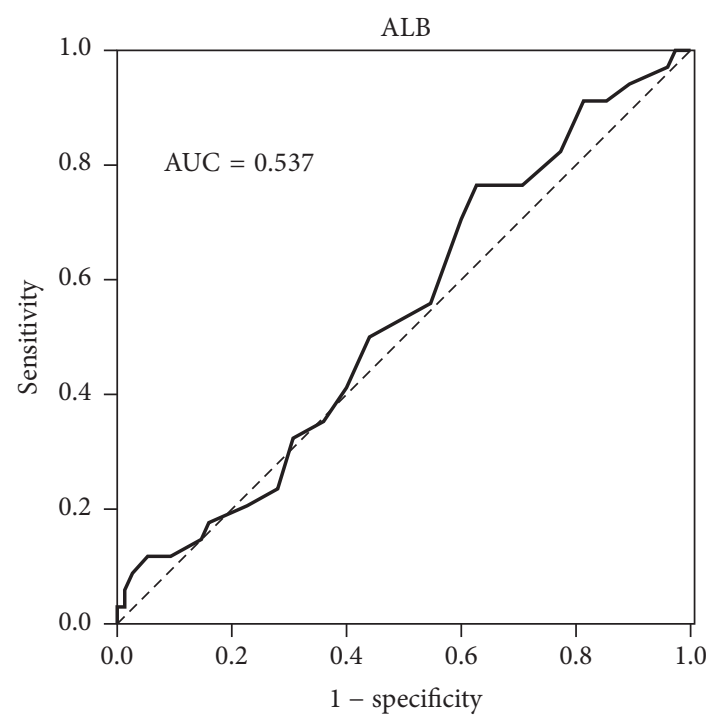

(a)

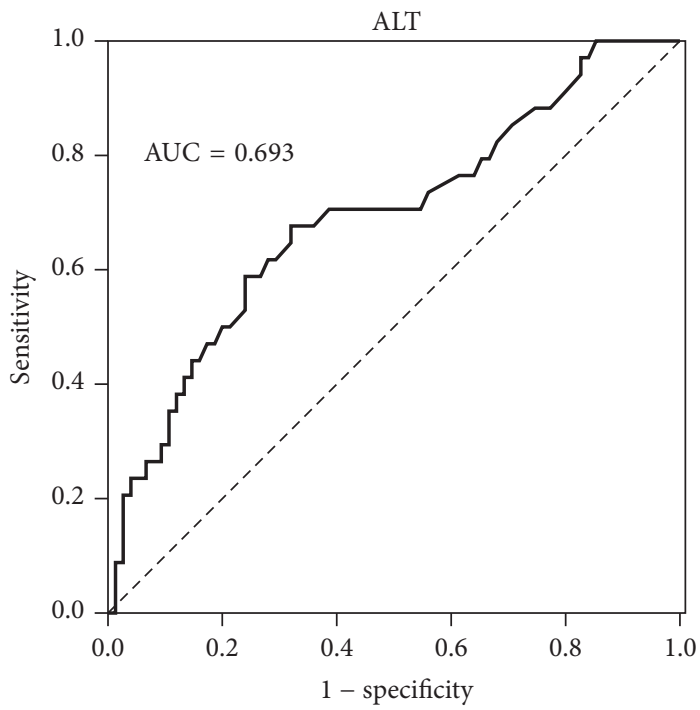

(c)

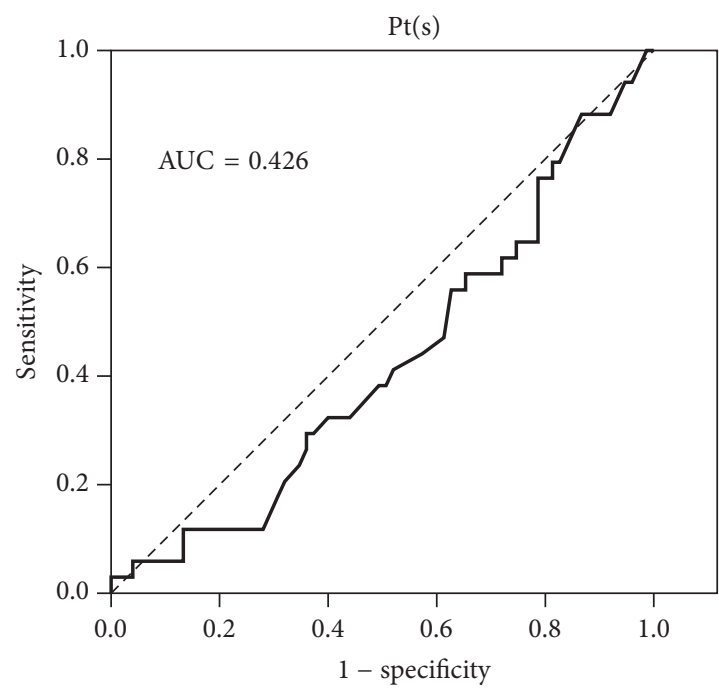

(e)

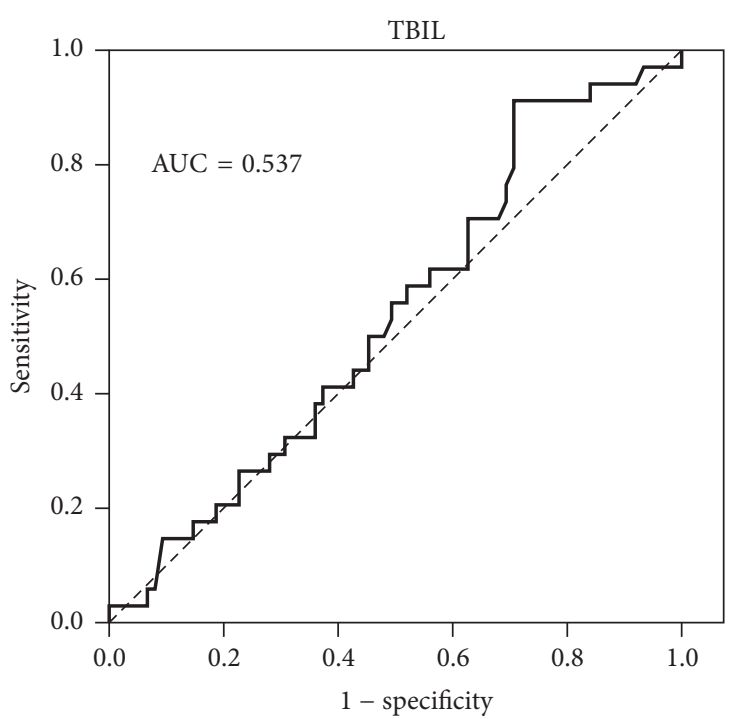

(b)

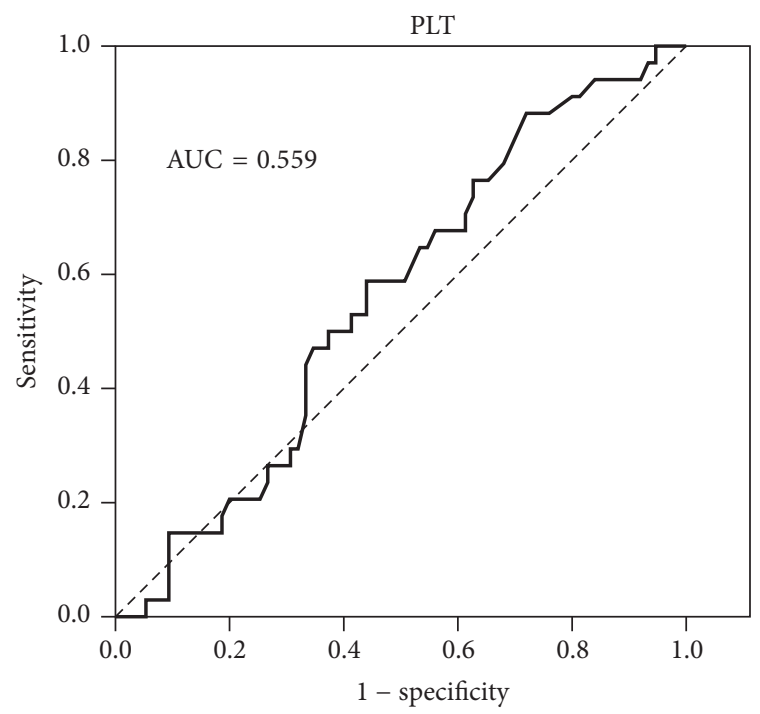

(d)

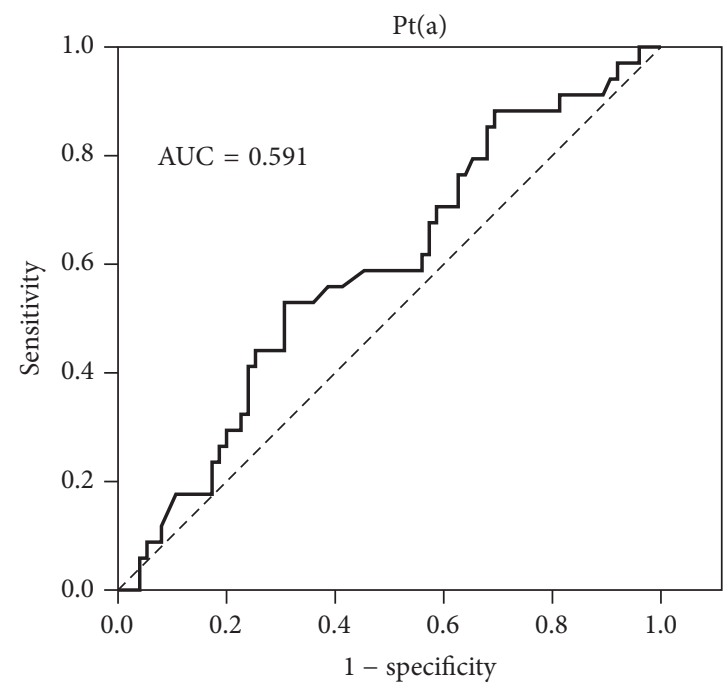

(f)

FIgURE 2: Continued. 


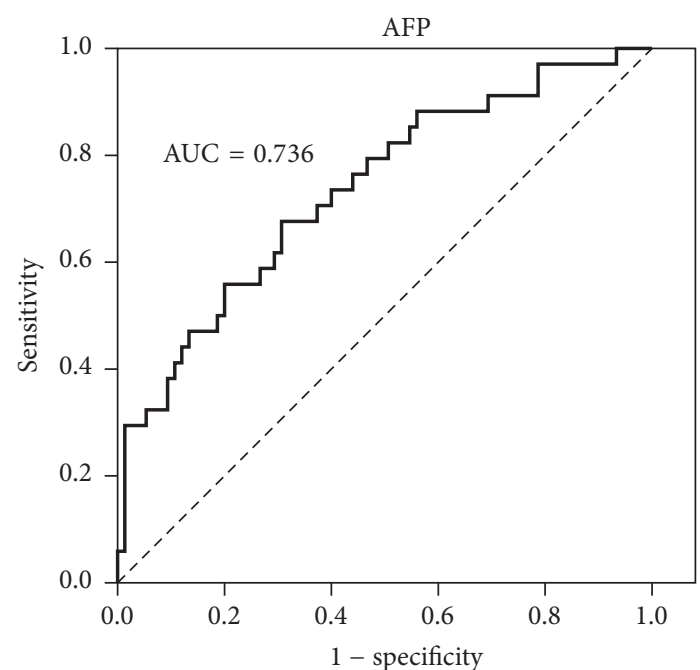

(g)

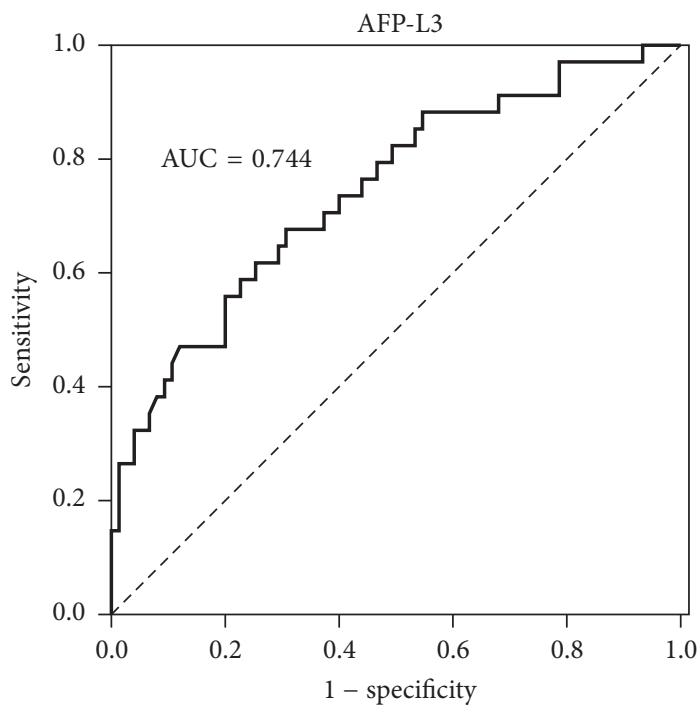

(i)

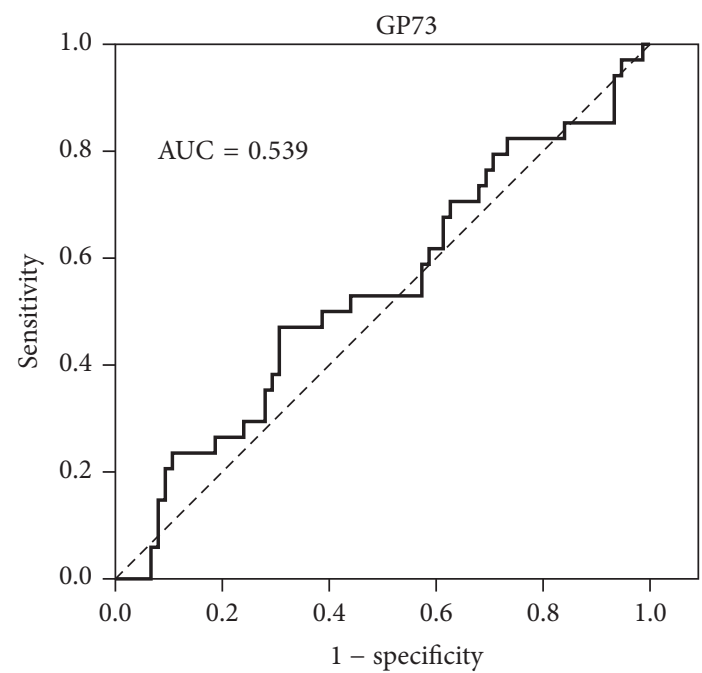

(h)

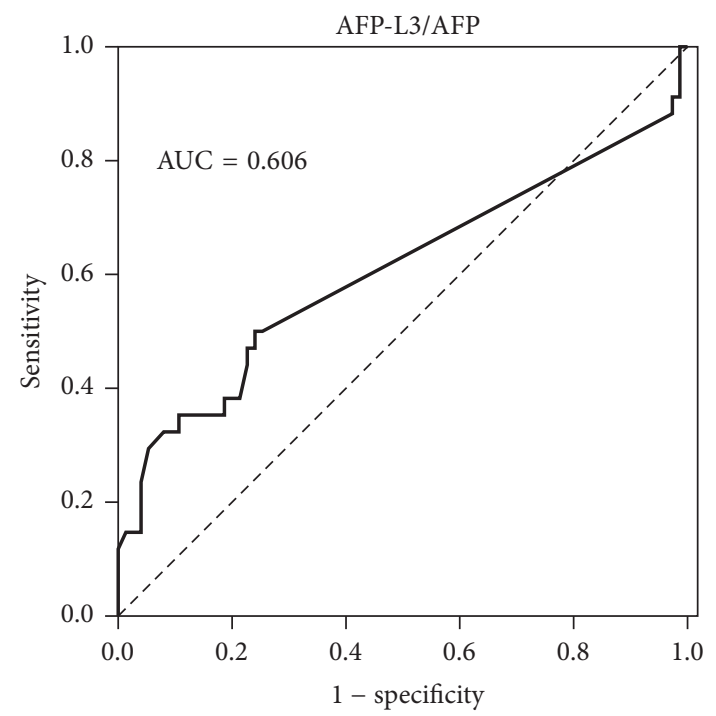

(j)

FIGURE 2: The ROC curves of 10 biomarkers for prediction of HCC in the cirrhotic patients.

TABLE 4: The predictive value of all markers and combination of 3 markers for HCC in cirrhotic patients.

\begin{tabular}{|c|c|c|c|c|c|c|c|}
\hline Markers & Area under ROC curve & Standard error & $p$ value & $95 \%$ confidence interval & Cut-off & Sensitivity & Specificity \\
\hline $\operatorname{ALB}(g / l)$ & 0.537 & 0.059 & 0.534 & $0.423-0.652$ & 28.5 & 0.765 & 0.373 \\
\hline TBIL $(\mu \mathrm{mol} / \mathrm{L})$ & 0.537 & 0.058 & 0.537 & $0.423-0.651$ & 15.15 & 0.912 & 0.293 \\
\hline $\operatorname{ALT}(\mathrm{U} / \mathrm{L})$ & 0.693 & 0.056 & 0.001 & $0.582-0.803$ & 44.5 & 0.676 & 0.680 \\
\hline $\operatorname{PLT}\left(10^{9} / \mathrm{L}\right)$ & 0.559 & 0.057 & 0.327 & $0.447-0.670$ & 45.5 & 0.882 & 0.720 \\
\hline $\mathrm{PT}(\mathrm{s})(\mathrm{s})$ & 0.426 & 0.058 & 0.216 & $0.311-0.540$ & 21.5 & 0.029 & 1.000 \\
\hline $\mathrm{PT}(\mathrm{a})(\%)$ & 0.591 & 0.058 & 0.128 & $0.477-0.705$ & 75 & 0.529 & 0.693 \\
\hline $\operatorname{AFP}(\mathrm{ng} / \mathrm{mL})$ & 0.736 & 0.052 & 0.000 & $0.634-0.839$ & 10.28 & 0.676 & 0.693 \\
\hline GP73 (ng/mL) & 0.539 & 0.061 & 0.513 & $0.419-0.659$ & 221.85 & 0.471 & 0.693 \\
\hline AFP-L3 (ng/mL) & 0.744 & 0.052 & 0.000 & $0.642-0.846$ & 0.514 & 0.676 & 0.693 \\
\hline L3/AFP ratio & 0.606 & 0.065 & 0.077 & $0.478-0.734$ & 0.052 & 0.500 & 0.760 \\
\hline $\mathrm{ALT}+\mathrm{AFP}+\mathrm{AFP}-\mathrm{L} 3$ & 0.770 & 0.050 & 0.000 & $0.672-0.868$ & 0.23 & 0.824 & 0.667 \\
\hline $\mathrm{ALT}+\mathrm{AFP}$ & 0.780 & 0.049 & 0.000 & $0.683-0.877$ & 0.24 & 0.824 & 0.693 \\
\hline ALT + AFP-L3 & 0.773 & 0.050 & 0.000 & $0.676-0.871$ & 0.23 & 0.824 & 0.680 \\
\hline AFP + AFP-L3 & 0.740 & 0.052 & 0.000 & $0.638-0.842$ & 0.23 & 0.676 & 0.693 \\
\hline
\end{tabular}


TABLE 5: The dynamic change of serum markers concentrations before and after HCC occurred.

\begin{tabular}{|c|c|c|c|c|c|c|}
\hline \multirow{2}{*}{ Markers } & \multicolumn{2}{|c|}{ Starting point (hepatic cirrhosis) } & \multicolumn{2}{|c|}{ End point (HCC) } & \multirow{2}{*}{$T / Z$ values } & \multirow{2}{*}{$p$ values } \\
\hline & $n$ & Statistical description & $n$ & Statistical description & & \\
\hline $\operatorname{ALB}(g / l)$ & 17 & $32(25-43)$ & 17 & $33(26-42)$ & -0.166 & 0.868 \\
\hline TBIL $(\mu \mathrm{mol} / \mathrm{L})$ & 17 & $21(4.8-49.5)$ & 17 & $19.6(9.3-39.2)$ & -1.154 & 0.248 \\
\hline $\operatorname{ALT}(\mathrm{U} / \mathrm{L})$ & 17 & $58(20-253)$ & 17 & $28.5(16-262)$ & -1.895 & 0.058 \\
\hline $\operatorname{PLT}\left(10^{9} / \mathrm{L}\right)$ & 17 & $79(29-165)$ & 17 & $61.5(34-225)$ & -0.762 & 0.446 \\
\hline $\mathrm{PT}(\mathrm{s})(\mathrm{s})$ & 17 & $13.2(11-15)$ & 17 & $13(11.3-15.7)$ & -0.719 & 0.472 \\
\hline $\mathrm{PT}(\mathrm{a})(\%)$ & 17 & $75.3(64.1-98.7)$ & 17 & $75.1(61.7-100.6)$ & -1.894 & 0.058 \\
\hline $\mathrm{AFP}(\mathrm{ng} / \mathrm{mL})$ & 17 & $74.6(2.34-469.9)$ & 17 & $136.2(2.96-1501)$ & -0.152 & 0.879 \\
\hline GP73 (ng/mL) & 17 & $194.6(66.12-350)$ & 17 & $154.2(13.14-275.4)$ & 2.212 & 0.041 \\
\hline AFP-L3 (ng/mL) & 17 & $8.8(0.12-77.45)$ & 17 & $28.8(0.15-361.5)$ & -0.544 & 0.586 \\
\hline AFP-L3/AFP ratio & 17 & $0.09(0.03-0.43)$ & 17 & $0.10(0.05-0.50)$ & -0.848 & 0.408 \\
\hline
\end{tabular}

Starting point: start time of this study; end point: the time the patients were diagnosed HCC; $n$ : number of patients.

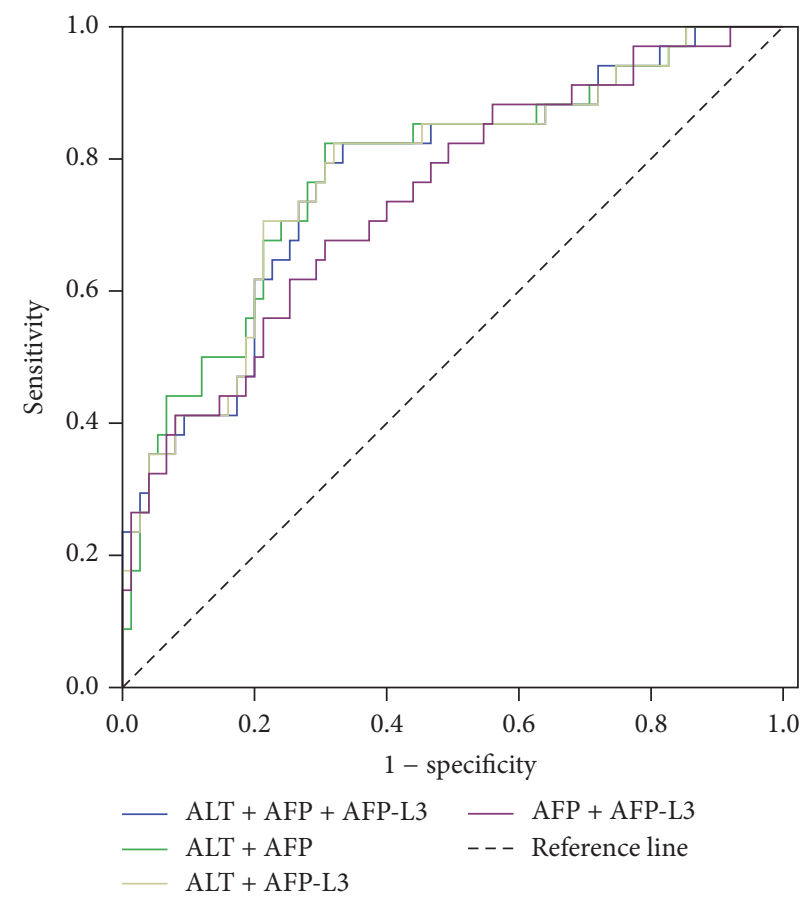

FIGURE 3: The multiple regression analysis with ALT, AFP, and AFP-L3 for predicting performance.

GP73 was $194.6(66.12-350) \mathrm{ng} / \mathrm{mL}$ in hepatic cirrhosis and $154.2(13.14-275.4) \mathrm{ng} / \mathrm{mL}$ in HCC. See Table 5 and Figure 4. It showed a gradually decreasing tendency of serum GP73 accompanied by the development of HCC from hepatic cirrhosis.

\section{Discussion}

In the past few decades, many promising candidate biomarkers for HCC had been found, but most of them were not applied to clinical diagnosis due to their limited practicability and high cost [15-19]. Nevertheless, these new markers have potential to be applied in clinical diagnosis for their higher sensitivity and specificity. So far, $\alpha$-fetoprotein (AFP) and imaging technology (e.g., ultrasound or computed tomography) are two primary methods to diagnose HCC in hospitals. AFP has been used as a serum marker for HCC for many years, but its sensitivity was only about 39\%-65\% [20]. AFPL3, which is the main glycoform of AFP in the serum of HCC, was proven to be an excellent biomarker with sensitivity $75 \%$ to $96.90 \%$. High percentage of AFP-L3 has been shown to be associated with poor differentiation and biologically malignant characteristics, worse liver function, and larger tumor mass; some experts thought that the AFP-L3/AFP ratio is more helpful in diagnosis and prognosis of $\operatorname{HCC}[21,22]$. However, Miura and his coworkers showed that AFP-L3 could not provide an entirely satisfactory solution to detect HCC at the early stage [23]. Our study showed that patients 


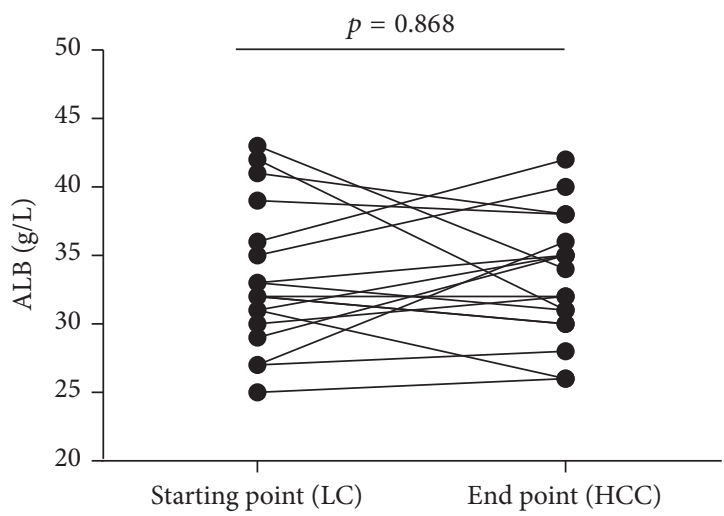

(a)

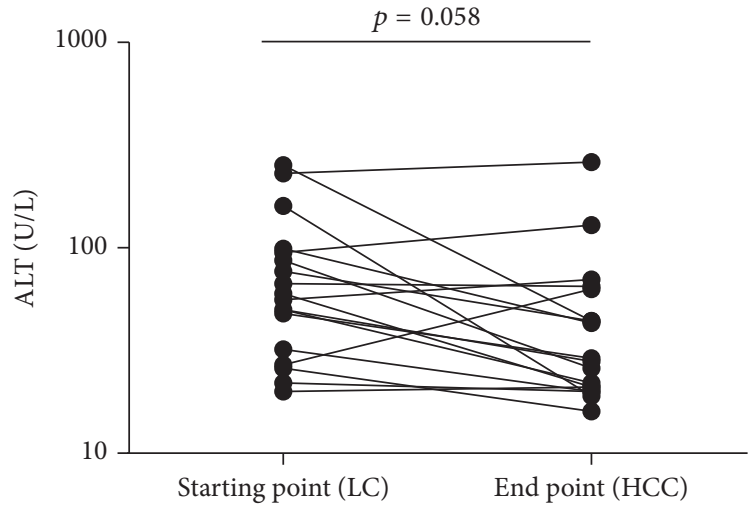

(c)

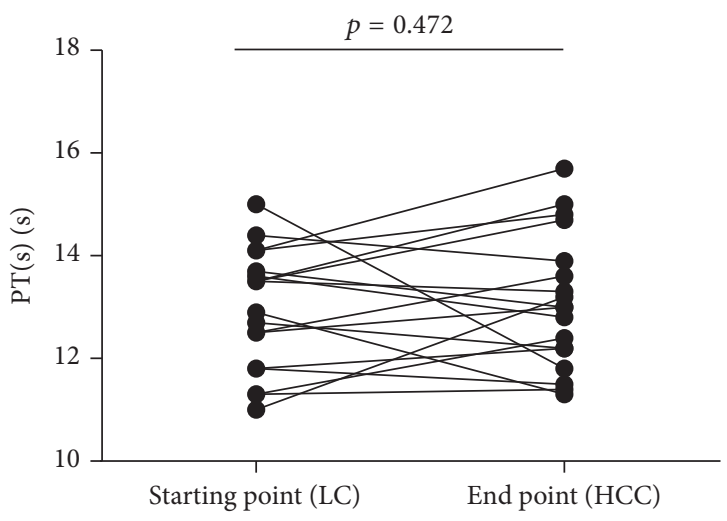

(e)

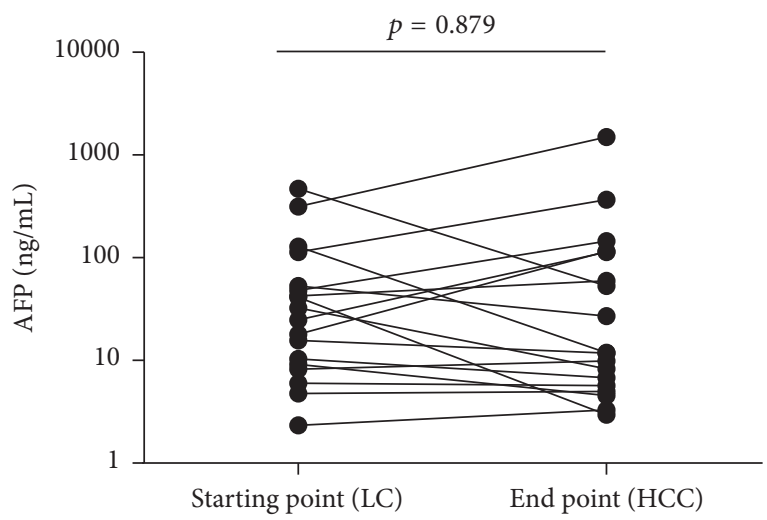

(g)

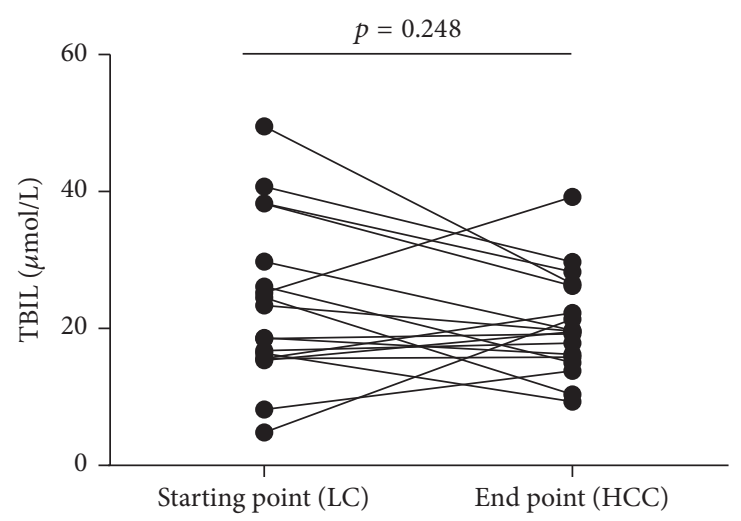

(b)

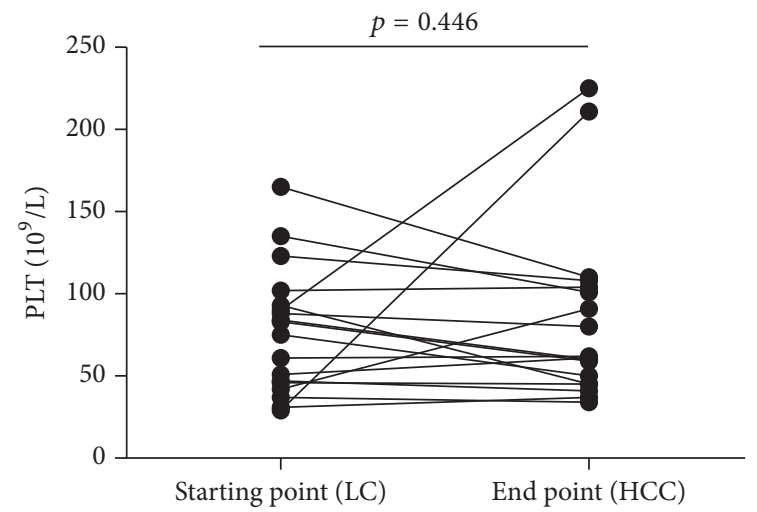

(d)

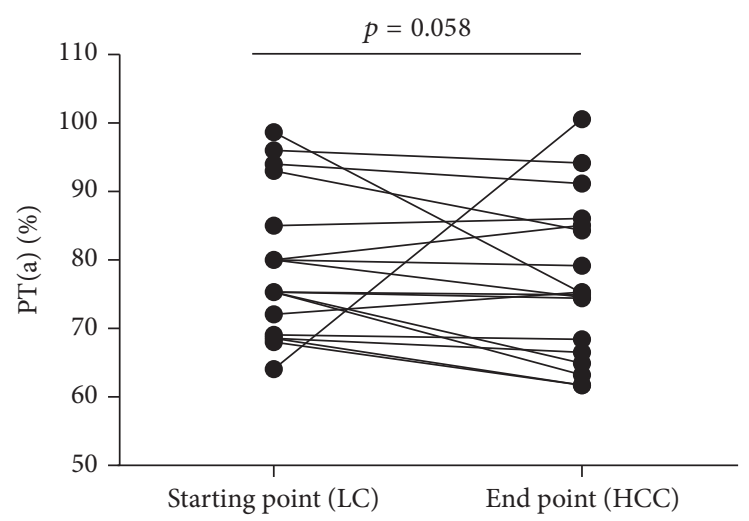

(f)

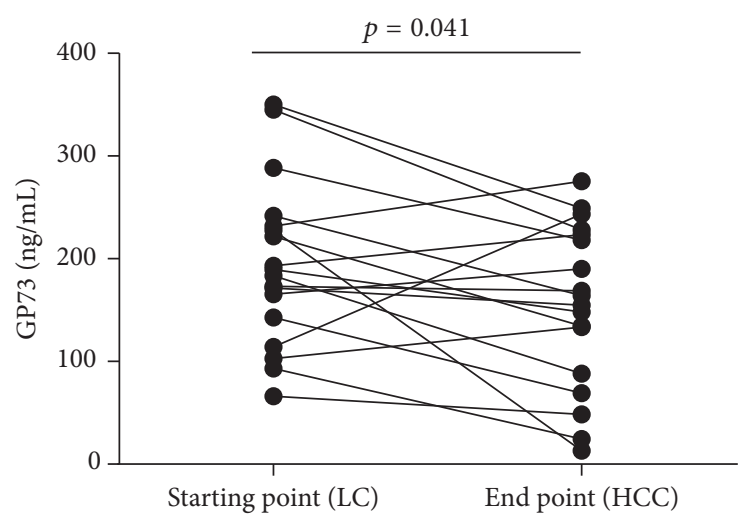

(h)

Figure 4: Continued. 


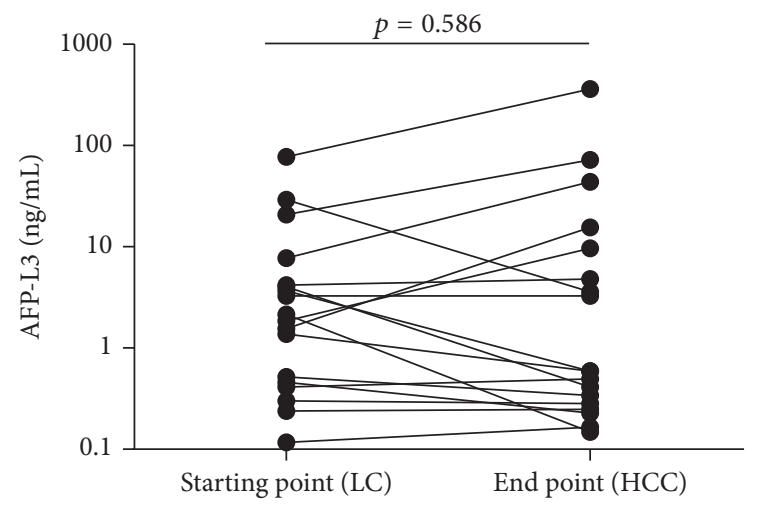

(i)

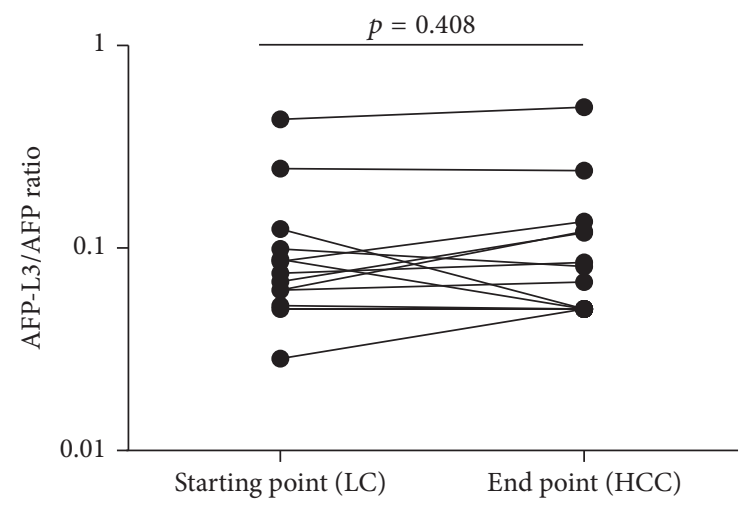

(j)

FIGURE 4: The plotting diagram of 10 biomarkers levels of patients who had developed HCC in starting point (hepatic cirrhosis) and end point (HCC).

with higher levels of AFP, AFP-L3, AFP-L3/AFP ratio, and ALT have higher risk of developing HCC than those with normal levels of these markers, suggesting that these four markers are potential precursors of HCC in hepatic cirrhosis patients and that serum AFP, AFP-L3, AFP-L3/AFP ratio, and ALT may be useful markers for indicating the development of HCC.

GP73 is a resident Golgi-specific membrane protein expressed by biliary epithelial cells in normal liver. A metaanalysis reported that GP73 is a valuable serum marker that seems to be superior to AFP and can be useful in the diagnosis and screening of HCC [11]. However, Tian et al. [24] indicated that GP73 elevated not only in HCC but also in other chronic liver diseases such as hepatic cirrhosis and hepatitis; even more, the concentration of GP73 in HCC (median $=107.3 \mu \mathrm{g} / \mathrm{L}$ ) was significantly lower than hepatic cirrhosis (median $=141.2 \mu \mathrm{g} / \mathrm{L}$ ) patients, but their conclusions may suffer from sample selection biases. In our study, followed-up experiments were conducted to assess the dynamic change of the serum markers during the progression of HCC. Our findings further confirm that serum GP73 level was significantly decreased during the progression of HCC. Some research results found that GP73 protein and mRNA expression increase gradually in chronic liver diseases, not only in the hepatocytes, but also in activated stellate cells which are the most important cell type in hepatic cirrhosis [25-27]. Therefore, maximal GP73 concentrations were observed in hepatic cirrhosis rather than in HCC.

\section{Conclusion}

Although this study is limited by the small sample size and short study duration, our data suggest that higher serum levels of AFP, AFP-L3, AFP-L3/AFP ratio, and ALT were risk factors associated with the development of HCC and the detection of GP73 has a certain guiding significance to predict the risk of HCC in hepatic cirrhosis patients; regular monitoring of these serum markers in hepatic cirrhosis patients is necessary.

\section{Conflicts of Interest}

The authors declare that there are no conflicts of interest.

\section{Authors' Contributions}

Bo Li and Boan Li contributed equally to this study.

\section{Acknowledgments}

This work was supported by the Capital Medical Development Project of China (2014-2-5031).

\section{References}

[1] H. B. El-Serag and K. L. Rudolph, "Hepatocellular carcinoma: epidemiology and molecular carcinogenesis," Gastroenterology, vol. 132, no. 7, pp. 2557-2576, 2007.

[2] J. M. Llovet, A. Burroughs, and J. Bruix, "Hepatocellular carcinoma," The Lancet, vol. 362, no. 9399, pp. 1907-1917, 2003.

[3] W. C. Maddrey, "Hepatitis B: an important public health issue," Journal of Medical Virology, vol. 61, no. 3, pp. 362-366, 2000.

[4] Z. Zhang, Y. Zhang, Y. Wang, L. Xu, and W. Xu, "Alphafetoprotein-L3 and Golgi protein 73 may serve as candidate biomarkers for diagnosing alpha-fetoprotein-negative hepatocellular carcinoma," OncoTargets and Therapy, vol. 9, pp. 123129, 2015.

[5] S. F. Altekruse, K. A. McGlynn, and M. E. Reichman, "Hepatocellular carcinoma incidence, mortality, and survival trends in the United States from 1975 to 2005," Journal of Clinical Oncology, vol. 27, no. 9, pp. 1485-1491, 2009.

[6] R. Siegel, D. Naishadham, and A. Jemal, "Cancer statistics, 2013," CA: A Cancer Journal for Clinicians, vol. 63, no. 1, pp. 11-30, 2013.

[7] V. Hernandez-Gea, F. Turon, A. Berzigotti, and A. Villanueva, "Management of small hepatocellular carcinoma in cirrhosis: focus on portal hypertension," World Journal of Gastroenterology, vol. 19, no. 8, pp. 1193-1199, 2013.

[8] J. Bruix and M. Sherman, "Management of hepatocellular carcinoma: an update," Hepatology, vol. 53, no. 3, pp. 1020-1022, 2011. 
[9] Y. Zhao, M. Wang, C. Cui et al., "Significance of combined tests of serum golgi glycoprotein 73 and other biomarkers in diagnosis of small primary hepatocellular carcinoma," Cancer Biomarkers, vol. 15, no. 5, pp. 677-683, 2015.

[10] Y.-X. Bao, Y. Yang, H.-R. Zhao et al., "Clinical significance and diagnostic value of Golgi-protein 73 in patients with earlystage primary hepatocellular carcinoma," Chinese Journal of Oncology, vol. 35, no. 7, pp. 505-508, 2013.

[11] C. D. M. Witjes, S. M. Van Aalten, E. W. Steyerberg et al., "Recently introduced biomarkers for screening of hepatocellular carcinoma: a systematic review and meta-analysis," Hepatology International, vol. 7, no. 1, pp. 59-64, 2013.

[12] Minister of Health of the People's Republic of China, "Guidelines for diagnosis and treatment of primary hepatocellular carcinoma," Chinese Clinical Oncology, vol. 16, no. 10, pp. 929946, 2011.

[13] Chinese Society of Hepatology and Chinese Society of Infectious Diseases, "The guidelines of prevention and treatment for chronic hepatitis B (2010 version)," Chinese Journal of Experimental and Clinical Infectious Disease (Electronic Version), vol. 5, no. 1, pp. 79-100, 2011.

[14] Chinese Society of Hepatology and Chinese Society of Infectious Diseases, "Guideline of prevention and treatment of hepatitis C," Zhonghua Yu Fang Yi Xue Za Zhi, vol. 38, no. 2, pp. 10-15, 2004.

[15] H. Shirakawa, H. Suzuki, M. Shimomura et al., "Glypican-3 expression is correlated with poor prognosis in hepatocellular carcinoma," Cancer Science, vol. 100, no. 8, pp. 1403-1407, 2009.

[16] M.-O. Riener, F. Stenner, H. Liewen et al., "Golgi phosphoprotein2 (GOLPH2) expression in liver tumors and its value as a serum marker in hepatocellular carcinomas," Hepatology, vol. 49, no. 5, pp. 1602-1609, 2009.

[17] S. Osada, M. Kanematsu, H. Imai, and S. Goshima, "Clinical significance of Serum HGF and c-Met expression in tumor tissue for evaluation of properties and treatment of hepatocellular carcinoma," Hepato-Gastroenterology, vol. 55, no. 82-83, pp. 544-549, 2008.

[18] S. T. Cheung, S. T. Fan, Y. T. Lee et al., "Albumin mRNA in plasma predicts post-transplant recurrence of patients with hepatocellular carcinoma," Transplantation, vol. 85, no. 1, pp. 8187, 2008.

[19] M. Ferracin, A. Veronese, and M. Negrini, "Micromarkers: MiRNAs in cancer diagnosis and prognosis," Expert Review of Molecular Diagnostics, vol. 10, no. 3, pp. 297-308, 2010.

[20] B. Daniele, A. Bencivenga, A. S. Megna, and V. Tinessa, " $\alpha$ fetoprotein and ultrasonography screening for hepatocellular carcinoma," Gastroenterology, vol. 127, pp. S108-S112, 2004.

[21] A. I. Gomaa, S. A. Khan, E. L. S. Leen, I. Waked, and S. D. Taylor-Robinson, "Diagnosis of Hepatocellular carcinoma," World Journal of Gastroenterology, vol. 15, no. 11, pp. 1301-1314, 2009.

[22] V. V. Khien, H. V. Mao, T. T. Chinh et al., "Clinical evaluation of lentil lectin-reactive alpha-fetoprotein-L3 in histology-proven hepatocellular carcinoma," International Journal of Biological Markers, vol. 16, no. 2, pp. 105-111, 2001.

[23] N. Miura, Y. Osaki, M. Nagashima et al., "A novel biomarker TERTmRNA is applicable for early detection of hepatoma," BMC Gastroenterology, vol. 10, article 46, 2010.

[24] L. Tian, Y. Wang, D. Xu et al., "Serological AFP/Golgi protein 73 could be a new diagnostic parameter of hepatic diseases," International Journal of Cancer, vol. 129, no. 8, pp. 1923-1931, 2011.
[25] R. D. Kladney, G. A. Bulla, L. Guo et al., "GP73, a novel Golgilocalized protein upregulated by viral infection," Gene, vol. 249, no. 1-2, pp. 53-65, 2000.

[26] R. Iftikhar, R. D. Kladney, N. Havlioglu et al., "Disease- and cellspecific expression of GP73 in human liver disease," American Journal of Gastroenterology, vol. 99, no. 6, pp. 1087-1095, 2004.

[27] R. D. Kladney, X. Cui, G. A. Bulla, E. M. Brunt, and C. J. Fimmel, "Expression of GP73, a resident golgi membrane protein, in viral and nonviral liver disease," Hepatology, vol. 35, no. 6, pp. 14311440, 2002. 

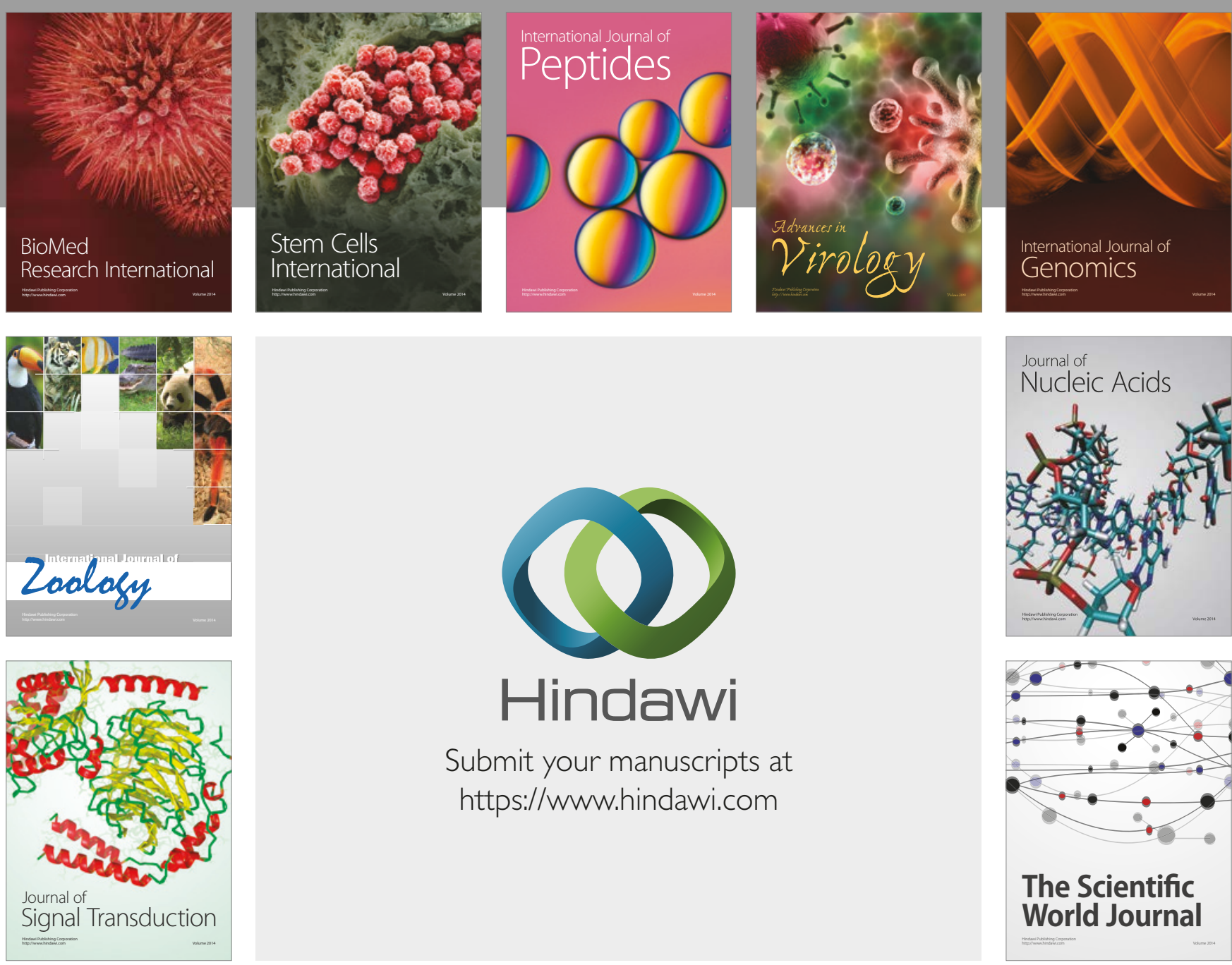

Submit your manuscripts at

https://www.hindawi.com
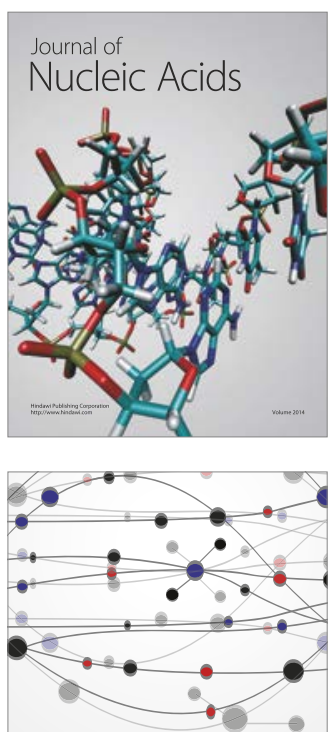

The Scientific World Journal

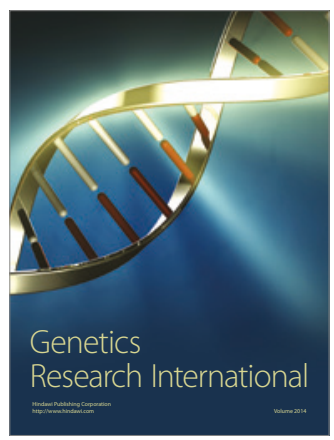

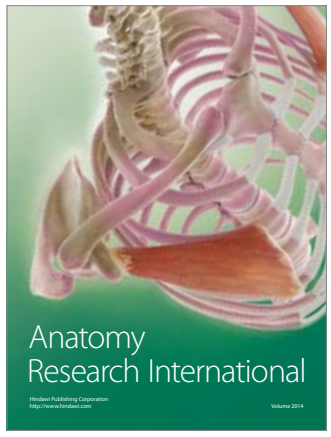

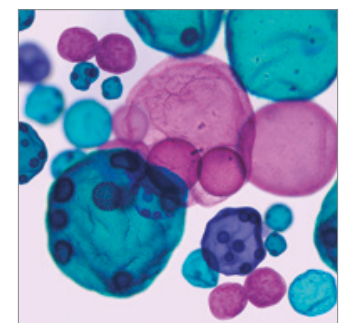

International Journal of Microbiology
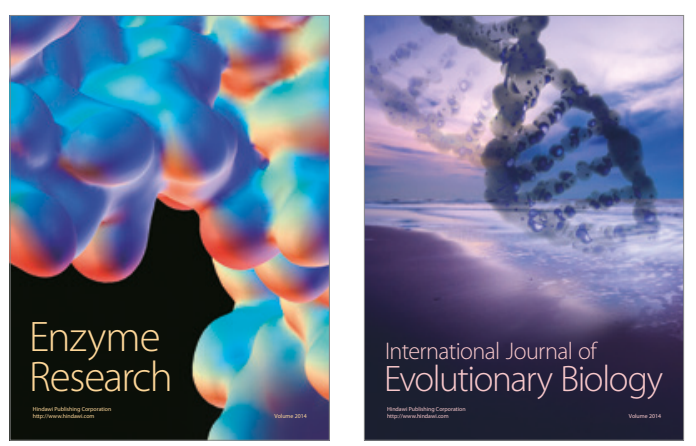
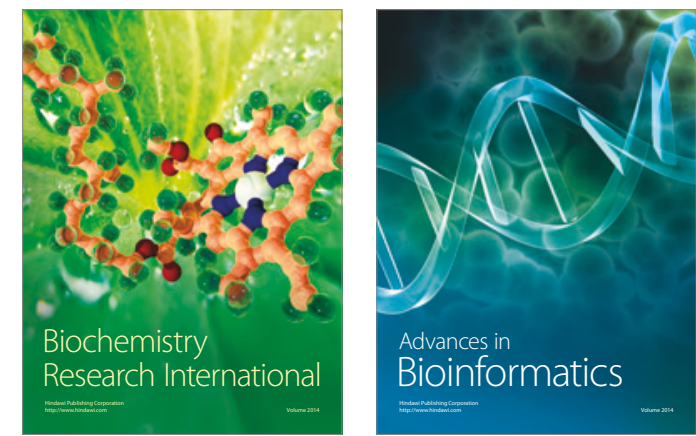

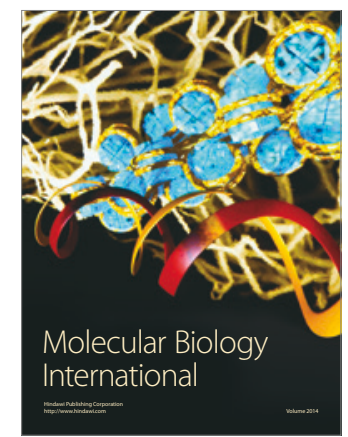

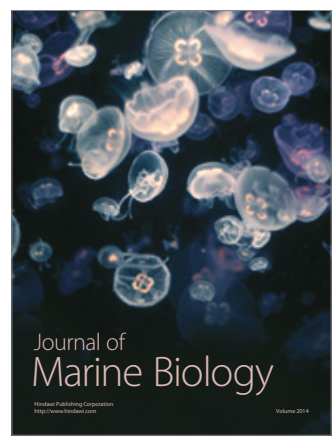

